\title{
Psychological risk factors associated with falls among elderly people in Baghdad city, Iraq
}

\author{
Mohammed A. Abdal Qader ${ }^{1^{*}}$, Rahmah Mohd. Amin ${ }^{2}$, Shamsul Azhar Shah ${ }^{1}$, Zaleha Md. Isa $^{1}$, \\ Khalib Abdul Latif ${ }^{1}$, Hasanain Faisal Ghazi ${ }^{1}$ \\ ${ }^{1}$ Department of Community Health, Universiti Kebangsaan Malaysia Medical Centre, Kuala Lumpur, Malaysia; \\ *Corresponding Author: dr_mohamed_aj@yahoo.com \\ ${ }^{2}$ Medical and Health Science Faculty, Universiti Sultan Zainal Abidin (City Campus), Jalan Sultan Mahmud, Kuala Terengganu, Malaysia
}

Received 15 August 2013; revised 21 September 2013; accepted 6 October 2013

Copyright (C) 2013 Mohammed A. Abdal Qader et al. This is an open access article distributed under the Creative Commons Attribution License, which permits unrestricted use, distribution, and reproduction in any medium, provided the original work is properly cited.

\section{ABSTRACT}

Background: Ageing of the population is one of the most important demographic facts that come to the foreground in the 21st century. Objective: To assess the relationship between psychological factors (depression, loneliness, using anti anxiety medication, fear from falls and internal displacement of the population) and falls among elderly people in Baghdad city, Iraq. Methods: A matched 1:1 community based casecontrol study involving 716 elderly respondents, recruited randomly from six Non Governmental Organization (NGO) in different areas of Baghdad. Interviews to each respondent were done accordingly. Geriatric depression scale (GDS) was used to assess the depression among the elderly people. Results: The minimum age for cases and controls was 60 years old while the maximum age for cases was $\mathbf{8 7}$ and for controls was 85 years old. The female was predominant than male, $53.6 \%$ to $46.4 \%$ respectively. The relation between depression, fear from fall, using anti anxiety medication, internal displacement and falls was statistically significant $(p<0.001)$. Conclusions: Psychological factor especially depression among elderly people is one of the important risk factors contributing to falls accident. Fear from falls, displacement and taking anti anxiety medication were also in significant relation.

Keywords: Falls; Elderly; Depression; Fear from Fall; Baghdad

\footnotetext{
*The authors declare that they have no conflict of interest.
}

\section{INTRODUCTION}

Ageing of the population is one of the most important demographic facts that come to the foreground in the 21st century. Psychological problems of depression, loneliness and dependency feelings are very common among elderly people. Another common issue is falls accident which has a great impact on or leads to many consequences such as bedridden, total dependence on others and can even cause death [1].

According to United Nations report in 2009, the percentage of $60+$ age population in Iraq was $3.9 \%$ for men and $5.6 \%$ for women, while the sex ratio in $60+$ age group was 70 men to each 100 women. Some elderly Iraqis have lost all their relatives over the past few years and now have to depend totally on themselves. Being unable to work because of age or poor health conditions, some of them have urged for begging in the streets and become homeless people while others are supported by their neighbours and relatives[2].

Falls accident could be preventable and is a promising issue to be dealt with in preventive medicine. Hence the public health experts should take into consideration, this preventive issue involving falls among the elderly people seriously. More research is needed to be done to reduce the burden of falls to the community. It is obvious that lack of knowledge about risk factors and how to prevent them will contribute to a high prevalence of falls. Therefore, lack of knowledge in this issue will lead to a lack of preventive actions that should be taken, thus resulting in more falls [3].

Psychological relationships to falls accident were less clear. However, depression and falls, which can be correlated to the decrease of functional independence, loss of physical fitness, reduced gait velocity and loss of muscle strength are due to immobility and lethargy, which are 
common in depression [4].

Fear of falling (FOF) is a major health problem among the elderly living in communities. This feeling can be expressed in older people both who have fallen and also in older people who have never experienced a fall. The main consequences were identified as a decline in physical and mental performance, an increased risk of falling and progressive loss of health-related quality of life [5]. A study by Elliott et al. [6] in eastern North Carolina, United States showed a significant relation between living alone and falls accident to themselves.

In Iraq, there are no available studies or literature review that assays the epidemiology and aetiology of falls, that could be considered as evidence that warrants some attention. The objective of this study is to assess the relationship between psychological factors and falls accident among elderly people in Baghdad city, Iraq.

\section{Methods}

A case control study matched by sex and age was conducted between January and March 2012 in Baghdad city, Iraq. 716 elderly respondents, recruited randomly from six Non Governmental Organization (NGO) in different areas of Baghdad; These NGOs provide social \& medical services to the community in Iraq. Severely ill respondents, using wheelchair, an elderly fall outside the home and elderly with severe psychosomatic disease were excluded from this study. Face to face interview to each respondent were done accordingly. Back-to-back trans-lation to the questionnaire was done (English-Arabic-English). GDS (geriatric depression scale) standardized questionnaire (Arabic version) was used to measure the level of depression among the elderly people [7].

A pre test of the questionnaire was carried out to improve the questionnaires and make it more understandable. This study was approved by the Research and Ethics Committee of Universiti Kebangsaan Malaysia Medical Centre. Code Number FF-017-2012, consent form was taken from the respondents.SPSS version 19 was used for statistical analysis of the data and Pearson chi-square test was performed with a level of significance $\mathrm{p}<0.05$.

\section{Results}

The minimum age for cases and controls was 60 years old while the maximum age for cases was 87 and for controls was 85 years old, the mean age for cases was 67.01 while mean age for controls was 66.28 years old. The female was predominant than male, $53.6 \%$ to $46.4 \%$ respectively. Other socio-demographic characteristics as shown in Table 1 showdifferences between cases and controls. Educational level was a significant contributor for the falls. The employment status was not significant risk factor, while, the monthly family income and marital status were significant risk factors for falls among elderly people.

Table 1 also shows the distribution of the respondents' depression, fear from fall and living alone. The fear from fall was significantly associated with fall accident and of $\mathrm{p}<0.001$, the odds ratio is 2.90 , with a $95 \%$ confidence interval ranging from 2.17 to 4 , showed that those who suffer from fear were about 3 times more susceptible to fall than those elderly who does suffer from fear of falling. For depression factor, the $\mathrm{p}$ value is significant ( $\mathrm{p}<0.001$ ), the odds ratio 2.8 , indicating that those elderly with depression is about 3 times more susceptible to fall than those elderly without depression. Living alone was not statistically associated with falls (p $=0.91$ ) with odds ratio of 1.03 , and $95 \%$ confidence interval extending from 1.49 to 1.58 .

Internal displacement was a significant risk factor of a $\mathrm{p}$ value $<0.001$, those who internally displaced were about 2 times more to falls as compared to non displaced elderly.

Elderly people using anti anxiety medications suffer a higher significant risk of falls with odds ratio of 2.3.

\section{Discussion}

Fall is still found to be one of the public health problems among elderly people; falls are a common and often devastating problem among older people, causing a tremendous amount of morbidity, mortality and use of health care services. The most important finding in our study was depression and fears from fall as they were significantly associated with an increased risk of being a faller.

Some of the limitations in this study are recall bias of the respondents, not an interventional type and logistic problems because of the security situation in Baghdad. While the strength of this study is mainly being a community based study, with large sample size and first kind of study in Iraq.

In this study, there is a significant difference between low education and high education among cases and controls, those with low education level were at odds of risk by about 1.8 times as compared to those with high education as shown in other studies $[8,9]$.

There was a significant relationship between monthly income and falls as supported by other studies. The possible reason for that could be those with higher monthly income can get better welfare life, nutrition and more medical services. There were no significant association between current employment status (working or not working) and fall and that was against what some other studies findings [8,9].

Fear from falls was associated with falls accident as 
Table 1. The Frequency distribution and relationship of socio-economic and psychological factors with falls accident among the elderly people in Iraq.

\begin{tabular}{|c|c|c|c|c|c|}
\hline Variables & Case (358) N (\%) & Control (358) N (\%) & p-value ${ }^{a}$ & POR & $95 \% \mathrm{CI}$ \\
\hline \multicolumn{6}{|c|}{ Educational level } \\
\hline Low & $189(52.8)$ & $130(36.3)$ & $<0.001^{*}$ & 1.96 & $1.45-2.64$ \\
\hline High & $169(47.2)$ & $228(63.7)$ & & & \\
\hline \multicolumn{6}{|c|}{ Employment status (current) } \\
\hline Unemployed & $270(75.4)$ & 254 (70.9) & 0.17 & 1.25 & $0.90-1.75$ \\
\hline Employed & $88(24.6)$ & $104(29.1)$ & & & \\
\hline \multicolumn{6}{|l|}{ Marital Status } \\
\hline Married & $159(44.4)$ & $224(62.6)$ & $<0.001^{*}$ & 2.12 & $1.56-2.85$ \\
\hline Not Married & 199 (55.6) & $134(37.4)$ & & & \\
\hline \multicolumn{6}{|l|}{ Monthly Income } \\
\hline Low Income & $192(53.6)$ & $164(45.8)$ & $0.036 *$ & 1.36 & $1.02-1.83$ \\
\hline High Income & $166(46.4)$ & $194(54.2)$ & & & \\
\hline \multicolumn{6}{|l|}{ Fear of Fall } \\
\hline Yes & $262(73.2)$ & $173(48.3)$ & $<0.001^{*}$ & 2.90 & $2.17-4.00$ \\
\hline No & $96(26.8)$ & $185(51.7)$ & & & \\
\hline \multicolumn{6}{|l|}{ Depression } \\
\hline Yes & $284(79.3)$ & 207 (57.8) & $<0.001^{*}$ & 2.80 & $2.01-3.89$ \\
\hline No & $74(20.7)$ & $151(42.2)$ & & & \\
\hline \multicolumn{6}{|c|}{ Living (Household) } \\
\hline Alone & 49 (13.7) & $50(14)$ & 0.91 & 1.03 & $1.49-1.58$ \\
\hline Not Alone & 309 (86.3) & $308(86)$ & & & \\
\hline \multicolumn{6}{|c|}{ Internal displacement } \\
\hline Yes & $133(37.2)$ & 77 (21.5) & $<0.001^{*}$ & 2.15 & $1.54-3.00$ \\
\hline No & 225 (62.8) & $281(78.5)$ & & & \\
\hline \multicolumn{6}{|c|}{ Anti anxiety medications } \\
\hline Yes & $142(39.7)$ & $80(22.3)$ & $<0.001^{*}$ & 2.32 & $1.66-3.22$ \\
\hline No & $216(60.3)$ & $278(77.7)$ & & & \\
\hline
\end{tabular}

${ }^{\mathrm{a}}$ Pearson chi-square test was performed; $*$ Level of significance $\mathrm{p}<0.05$; POR $=$ Prevalence odds ratio.

supported by Yu et al. study, they found that the total rate of falls-induced fear of repeated episodes of falls (58.8\%) and at the same time the occurrence of falls were significantly associated with fear of future falls [9].

Kwan et al. in their systematic review found that the median fall rates was $18 \%$, they found that being complaining of fear of falling was commonly reported factor [10]. On the other hand, study by Leung et al. did not match our findings as fear from fall was not significantly associated with falls [11], this contradictory could be due to the differences in the culture, habits and welfare between these two different societies.

While for depression factor, our study was supported by other studies which found that falls were most strongly associated with sad feeling or depression [12,13].

Living alone was one of the risk factors has been studied, in our study it was not significantly associated with falls and other studies supported our findings, as the study done in the city of Mataró, Spain, they stated that no significant difference was found between the proportion of falls in people living alone (34.3\%) or accompanied (31.7\%) [14], in another study in Brazil found no significant association between living with a partner and fall [13].

According to United Nations High Commissioner for Refugees (UNHCR), internal displacement remains a 
major problem, and internally displaced persons (IDPs) require continued assistance and protection from UNHCR until a dignified solution is found to their troubles. Families live in poor settlements without adequate shelter and with limited access to water, electricity, schools and health centers [15].

Using anti anxiety drugs were associated with falls as supported by a study done in Great Britain, they found that hypnotics and anti anxiety drugs was independently associated with an increased odds of falling, it was associated with an increase of about $50 \%$ in the odds of falling [16]. Another study found that sleeping pills won't increase elderly fall risk, they found that it's insomnia itself, not sleeping pills, that increases the risk for falls and injuries among elderly people [17].

\section{Conclusion}

Psychological factor especially depression among elderly is one of the important risk factors contributing to falls. Also, fear from falls, displacement and taking antianxiety medications are significant risk factors of falls.

\section{Recommendations}

Findings from this research enhance knowledge about the contributing fall-related factors in elderly. Insights gained from this research will assist community and public health leaders and health care professionals in developing more effective intervention strategies to prevent or decrease falls, and associated psychological and physical consequences

To prevent falls, it is necessary to intervene on factors associated with falls. Methods include encouraging regular physical activity to improve equilibrium and muscle strength and the continuous monitoring of health status to prevent further deterioration.

Fall prevention is needed for elderly individuals living in the community and should target the elderly adults with less education level and low monthly income while helping to ensure that individuals who are living without family have the appropriate support.

\section{ACKNOWLEDGEMENTS}

This study was funded by the Universiti Kebangsaan Malaysia Medical Centre Fundamental Research Grant, Code Number FF-0172012 without which the study would not have been possible.

\section{REFERENCES}

[1] Graafmans, W.C., Ooms, M.E., Hofstee, H.M.A, Bezemer, P.D., Bouter, L.M. and Lips, P. (1996) Falls in the elderly: A prospective study of risk factors and risk profiles. American Journal of Epidemiology, 143, 11. http://dx.doi.org/10.1093/oxfordjournals.aje.a008690
[2] UN Office for the Coordination of Humanitarian Affairs (2007) IRAQ: Elderly most vulnerable to insecurity IRIN, the humanitarian news and analysis service of the integrated regional information networks, UN-OCHA, Baghdad city.

[3] Tremblay Jr. K.R. and Barber, C.E. (2010) Preventing falls in the elderly. http://www.ext.colostate.edu/pubs/consumer/10242.html

[4] Rao, S.S. (2005) Prevention of falls in older patients. American Family Physician, 72, 81-88.

[5] Scheffer, A.C., Schuurmans, M.J., van Dijk, N., van der Hooft, T. and de Rooij SE. (2008) Fear of falling: Measurement strategy, prevalence, risk factors and consequences among older persons. Age and Ageing, 37, 19-24. http://dx.doi.org/10.1093/ageing/afm169

[6] Elliott, S., Painter, J. and Hudson, S. (2009) Living alone and fall risk factors in community-dwelling middle age and older adults. Journal of Community Health, 34, 301310. http://dx.doi.org/10.1007/s10900-009-9152-x

[7] Samira, N. (2011) http://www.stanford.edu/ yesavage/GDS.html

[8] Morgan Robert, O., Virnig Beth. A., Maurice, D., Elsayed A.-M. and Carolee A. De V. (2003) Low-intensity exercise and reduction of the risk for falls among at-risk elders. The Journals of Gerontology, 59, M1062-M1067. http://biomedgerontology.oxfordjournals.org/content/59/1 0/M1062.short-aff-1

[9] Yu, P.L., Qin, Z.H., Shi, J., Zhang, J., Xin, M.Z., Wu, Z.L. and Sun, Z.Q. (2009) Prevalence and related factors of falls among the elderly in an urban community of Beijing. Biomedical Environmental Sciences, 22, 179-187. http://dx.doi.org/10.1016/S0895-3988(09)60043-X

[10] Kwan, M.M., Close, J.C., Wong, A.K. and Lord, S.R. (2011) Falls incidence, risk factors, and consequences in Chinese older people: A systematic review. Journal of the American Geriatric Society, 59, 536-543. http://dx.doi.org/10.1111/j.1532-5415.2010.03286.x

[11] Leung, A., Chi, I., Lou, V.W. and Chan, K.S. (2010) Psychosocial risk factors associated with falls among Chinese community-dwelling older adults in Hong Kong. Health \& Social Care in the Community, 18, 272-281.

[12] Stevens, J.A., Ballesteros, M.F., Mack, K.A., Rudd, R.A., DeCaro, E. and Adler, G. (2012) Gender differences in seeking care for falls in the aged Medicare population. American Journal of Preventive Medicine, 43, 59-62. http://dx.doi.org/10.1016/j.amepre.2012.03.008

[13] Juliana, G., Lucy, G., Otávio de T.N. and Marcelo, P.R. (2010) factors related to falls among elderly women resident in a community. Revista da Associação Médica Brasileira, 56, 327-332.

[14] Salvà, A., Bolíbar, I., Pera, G. and Arias, C. (2004) Incidence and consequences of falls among elderly people living in the community. Medicina Clinica (Barc), 122, 172-176. http://dx.doi.org/10.1016/S0025-7753(04)74184-6

[15] United Nations High Commissioner for Refugees (2012) 2012 UNHCR country operations profile, Iraq, UNHCR, Baghdad city. 
[16] Lawlor, D.A., Patel, R. and Shah, E. (2013). Association between falls in elderly women and chronic diseases and drug use: Cross sectional study. BMJ, 327, 712.
[17] Alon, A. (2005) Sleeping pills won’t increase elderly fall risk. Health Day News, University of Michigan Health System. 